\title{
Skull Base Chordoma
}

National Cancer Institute

\section{Source}

National Cancer Institute. Skull Base Chordoma. NCI Thesaurus. Code C5453.

A slow-growing malignant bone tumor arising from the remnants of the notochord and occurring in the base of the skull. It is characterized by a lobulated growth pattern, myxoid stroma formation, and the presence of physaliphorous cells.. 